October 12, 2001

\title{
The Life Cycles of Industrial Plants
}

\author{
Michael Gort and Seong-Hoon Lee*
}

\begin{abstract}
The paper presents a dynamic programming model with multiple classes of capital goods to explain capital expenditures on existing plants over their lives. The empirical specification shows that the path of capital expenditures is explained by (a) complementarities between old and new capital goods, (b) the age of plants, (c) an index that captures the rate of technical change and (d) the labor intensiveness of a plant when it is newly born. The model is tested with Census data for roughly 6,000 manufacturing plants that were born after 1972 .
\end{abstract}

Key words: Investment, Complementarity, Plant lives, Technical change.

JEL Classification:D24, O30

\footnotetext{
${ }^{*}$ State University of New York at Buffalo.
} 


\section{The Life Cycles of Industrial Plants}

In the beginning, so Genesis tells us, God created the heaven and the earth. And the earth was without form. Unlike the earth, new industrial plants are not, initially, without form, but that form appears to be highly malleable over time. This contrasts with the familiar putty-clay model that assumes great flexibility in the choice of inputs before a plant is built, and virtually no choice after its initial construction. It therefore assumes that plants are built in a single act of creation. The world of plant investment is very different from this. For manufacturing plants for which there is a continuous record for more than twenty years, more than two thirds of the cumulative outlays for plant and equipment over the twenty years occurs after the first three years of the plant's life. And even for plants for which there is a record for only ten years, roughly half of the cumulative investment over ten years takes place after the first three years of life. ${ }^{1}$

We know, moreover, that there is considerable bunching of investment outlays over time at the plant level. Following a new plant's initial construction, the first peak in investment on the average occurs as early as the sixth year, and the second peak in the ninth year. Since the average life of manufacturing equipment (as estimated by the Bureau of Economic Analysis ${ }^{2}$ ), which reflects the effects of obsolescence as well as wear and tear, is generally much longer, it is obvious that the afore-mentioned investment does not arise from the need to replace worn out equipment. Indeed, the investment

\footnotetext{
1 . This is based on Census data on the investment histories of roughly 6,000 new manufacturing plants in the period after 1973.

2 . U.S. Bureau of Economic Analysis, "Methodology, Fixed Reproducible Tangible Wealth in the United States, 1925-94," http://www.bea.doc.gov/bea/mp.htm, M27-33.
} 
cycles in the first 15-20 years of a plant's life encompass not only equipment but also investment in structures, for which service lives exceed thirty years.

Why do firms choose to add capital to old plants, or replace the equipment of old plants that is physically still functional, rather than investing in completely new production facilities. Surely the choice of capital goods is less constrained in a new than in an old plant. If replacement of equipment is justified because technical change renders new equipment more efficient, is not the flexibility of such choice greater when it is not constrained by the requirement of compatibility with old assets?

There are three reasons why investment in old plants is chosen. (a) New assets do not operate independently of old assets but interact with them. Consequently, relatively small additions or replacements can often greatly augment the output of the combination of old and new assets. ${ }^{3}$ (b) Assets obsolesce at very different rates rendering partial replacement for obsolescence a cost-effective option. (c) Initial investments in assets are seldom perfectly balanced. Incremental capacity costs very little for some assets and a great deal for others. ${ }^{4}$ Consequently, there is usually spare capacity in some assets to accommodate later additions to others.

Plants, however, do not have infinite lives. Technical change leads to progressive obsolescence of old assets. While one consequence of obsolescence is the creation of opportunities for replacing old with more efficient new assets, the adaptability of old to new assets steadily declines. Hence over the long-run new investment on an old plant will gradually decline as a plant ages and technical change continues leading to the eventual

\footnotetext{
3 . A dramatic example of this is the addition of high pressure pumps to oil refineries which greatly raises the throughput of refineries.

4 . For example, ducts for wiring usually provide at little additional cost spare capacity for later additions to wiring.
} 
death of the plant. But the pattern of investment on old plants is quite complex, and for a more precise explanation, we turn to our formal model.

Section 1 presents our formal model. Section 2 describes the data and the observed investment patterns. Section 3 presents the estimates for the empirical specification of our model. Section 4 concludes with some brief observations of the implications of our results for the comparative analysis of economic growth and for studies of entry barriers.

\section{Formal Model}

The literature on capital investment has taken one of two directions with respect to adjustment costs of capital stocks: the convex and the non-convex adjustment cost models. The standard neoclassical theory of investment with convex adjustment costs, as reflected in Lucas (1967) and Gould (1968), implies a gradual and smooth expansion of capital stock to the desired level. As, however, Hayashi (1982) made clear, investment behavior with convex adjustment costs is not sufficient to explain spikes and lumpiness in investment. Models of investment behavior have, therefore, increasingly relied on the assumption of non-convexity. This, for example, is reflected in Rothschild (1971) and Bertola and Caballero (1990). The relevant literature is reviewed in Pindyck (1991) while Cooper, Haltiwanger and Power (1999) generate an empirical model to explain spikes in investment at the macroeconomic level, and Doms and Dunne (1994) at the microeconomic plant level, in both cases based on the assumption of non-convexity. However, neither the assumption of convexity nor of non-convexity by itself adequately explains both the observed spikes in investment behavior and the continuing 
process of partial substitution of new for older capital goods in response to technical change. To do so requires abandoning the construct of a single, homogeneous capital stock.

Boddy and Gort (1971) pointed to some implications of non-homogeneity by showing systematic differences between new and older plants in the ratio of capital outlays on structures to total capital expenditures, while Feldstein and Rothschild (1974) showed how changing the assumptions of homogeneous capital and geometric decay can produce lumpy investment patterns. The most direct foundation for this paper, however, is Jovanovic and Stolyarov (2000) who introduce a model with two capital goods: structures and equipment or, alternatively, old capital and new capital. Within the context of complementary goods, they incorporate non-convex costs of quality adjustment to explain spikes in investment.

With this as a starting point, we develop a dynamic optimization model with $n$ types of capital goods. These are assumed to be complementary both across capital goods of different age and of different type. We also distinguish the process with $n$ types of capital goods, between capacity additions and outlays on replacement. The model is then tested with data at the plant level. In brief, we find support for (a) the assumption of complementarity between old and new capital goods and (b) the conclusion that a combination of both convex and non-convex adjustment cost processes is needed to explain the observed phenomena.

Consider the optimization problem of a plant acting to maximize discounted lifetime net profits

(1) $\sum_{t=0}^{\infty} \beta^{t}\left[\pi_{t}-C_{t}\right]$, 
where $\beta \in(0,1)$ denotes the discount rate, $\pi_{t}$ profits and $C_{t}$ the cost of purchasing investment goods at time $t$. The plant production function at any point in time consists, as arguments, of a vector of $n$ types of capital goods plus a vector of all other $m$ types of inputs necessary for production. Let $Y_{t}=F\left(\mathbf{K}_{\mathbf{t}}, \mathbf{X}_{\mathbf{t}}, T_{t}\right)$ be the homothetic plant production function ${ }^{5}$ where $T_{t}$ denotes an exogenously given industry rate of technical change, $\mathbf{K}_{\mathbf{t}}=\left(K_{1 t}, K_{2 t}, \ldots, K_{n t}\right)$, a vector of capital goods, and $\mathbf{X}_{\mathbf{t}}=\left(X_{1 t}, X_{2 t}, \ldots, X_{m t}\right)$, a vector of all other inputs. Then, assuming a constant output price for the plant, the profit of the plant is written as

$$
\pi_{t}=P_{t} F\left(\mathbf{K}_{\mathbf{t}}, \mathbf{X}_{\mathbf{t}}, T_{t}\right)-\sum_{j=1}^{m} w_{j t} X_{j t},
$$

where $P_{t}$ denotes the output price and $w_{j t}$ is the price of input $X_{j t}$ at time $t$. The plant may add to existing capital goods or replace old with new ones, so that the cost function of each investment is written as

$$
c_{i t}=\left(1-\theta_{i t}\right) \frac{b_{i t+1}}{2} I_{i t+1}^{2}+\theta_{i t} p_{i t} K_{i t}
$$

where $\theta_{i t}=\{0,1\}$ with $p, b$ and $I$ denoting, respectively, the price of the replacement investment, the price of the added investment and the amount of added investment in capital good $i$. When investment is added to old capital good $i, \theta_{i t}=0$ and when capital good $i$ is replaced, $\theta_{i t}=1$. That is, $c_{h t}=p_{h t} K_{h t}$ if capital good $h$ is replaced and $c_{i t}=\frac{b_{i t+1}}{2} I_{i t+1}{ }^{2}$ if investment is added to the old capital good $i$. This assumes that the cost

\footnotetext{
${ }^{5}$. For example, we can think of a homothetic plant production function such that
} 
of adding to old capital goods is an increasing and convex function of $I$.

Notwithstanding this, for reasons specified later, some lumpiness of investment is to be expected.

For the accumulation of capital goods, it is assumed that capital goods obsolesce at different rates and that each capital good's rate of obsolescence is a function of its rate of technical change. Let $\delta_{i t}=\delta\left(T_{i t}\right)$ be the rate of obsolescence specific to technology index $T_{i t}$ of each capital good at time $t$. New capital good $h$ interacts with old capital good $i$ but less efficiently than if capital good $i$ were new. For this reason, technical change in capital good $h$ leads to obsolescence in capital good $i$.

Let $q_{i t}=q\left(T_{i t}\right)$ be the quality index of input $i$ specific to technology index $T_{i t}$ at time $t$. The quality of each capital good increases with technical change. Therefore, the accumulation of each capital good evolves as follows

$$
K_{i t+1}=G_{i}\left(K_{i t}, I_{i t+1}\right)=\left\{\begin{array}{l}
\left(1-\delta\left(T_{i t}\right)\right) K_{i t}+I_{i t+1} \\
q\left(T_{i t}\right) K_{i t}
\end{array}, \text { if } \theta_{i t}=\left\{\begin{array}{l}
0 \\
1
\end{array},\right.\right.
$$

where $\partial \delta\left(T_{i t}\right) / \partial T_{i t}>0$ and $\partial q\left(T_{i t}\right) / \partial T_{i t}>0$.

The plant maximizes (1) with $\pi$ and $C=\Sigma c_{i}$ defined by (2) and (3), respectively, subject to (4). The dynamic programming problem for this analysis where $\mathbf{K}_{\mathbf{t}}$ is a vector of state variables satisfies the following functional equation:

$$
V\left(\mathbf{K}_{\mathbf{t}}\right)=\max \left\{\mathbf{V}^{l}\left(\left(\mathbf{K}_{\mathbf{t}}\right)\right\},\right.
$$

$$
F\left(\mathbf{K}_{\mathbf{t}}, \mathbf{X}_{\mathbf{t}}, T_{t}\right)=T_{t}\left[\sum_{i=1}^{n} K_{i t}^{\mu}\right]^{\alpha / \mu} \prod_{j=1}^{m} X_{j t}^{\alpha} j \text {, where } \mu<1 \text { and } \sum_{j=0}^{m} \alpha_{j}=1 \text {. }
$$


where $\mathbf{V}^{l}\left(\left(\mathbf{K}_{\mathbf{t}}\right)\right.$ denotes a vector of all $2^{n}$ possible value functions with combinations of replaced and added investments. When added investments (capacity additions) for all capital goods are considered, the dynamic programming problem is

$$
V^{A}\left(\mathbf{K}_{\mathbf{t}}\right)=\max _{\left\{X_{j t}\right\}_{j=1}^{m},\left\{I_{i t+1}\right\}_{i=1}^{n}}\left\{\pi_{t}\left(\mathbf{K}_{\mathbf{t}}, \mathbf{X}_{\mathbf{t}}, T_{t}\right)-\frac{1}{2} \sum_{i=1}^{n} b_{i t+1} I_{i t+1}{ }^{2}+\beta V\left(\mathbf{K}_{\mathbf{t}+\mathbf{1}}\right)\right\},
$$

subject to $\mathbf{K}_{\mathbf{t}+\mathbf{1}}=\left(\left(1-\delta\left(T_{1 t}\right)\right) K_{1 t}+I_{1 t+1}, \ldots,\left(1-\delta\left(T_{n t}\right)\right) K_{n t}+I_{n t+1}\right)$. The optimal added investment to each old capital good is

$$
I_{i t+1}=\frac{1}{\beta\left[1-\delta\left(T_{i t}\right) b_{i t+1}\right]}\left[b_{i t} I_{i t}-\beta \frac{\partial H_{t}}{\partial K_{i t}}\right] \text {, }
$$

where $H_{t}=H\left(\mathbf{K}_{\mathbf{t}}, \mathbf{w}_{\mathbf{t}}, T_{t}\right)^{6}$. This function implies that the added investment of each capital good depends not only on the initial amount of that capital good but also on the initial amount of all other capital goods. As a plant ages, this optimal added investment to old capital goods has the properties: $\partial I_{i t} / \partial t<0$ and $\partial I_{i t} \partial T_{t-1}<0$. That is, investment that adds to the stock of each capital good $i$ (capacity additions) is positive with a decreasing rate over time so that, absent replacement investment, total investment eventually goes to zero.

We have thus far presented a model for capacity additions that relies on assumptions of convexity in costs. We noted earlier, however, that investment in new plants normally consists of complementary capital goods that are not perfectly balanced in terms of their capacity. Since capital goods vary greatly in cost, some unevenness in

\footnotetext{
${ }^{6}$. With a homothetic production function given by footnote 5 , it becomes $H_{t}=\alpha_{0}\left[P T_{t} \prod_{j=1}^{m}\left(\frac{\alpha_{j}}{w_{j t}}\right)^{\alpha}\right]^{\frac{1}{\alpha_{0}}}\left[\sum_{i=1}^{n} K_{i t}^{\mu}\right]^{\frac{1}{\mu}}$.
} 
outlays will follow from the non-concurrent exhaustion of capacity for less and more expensive capital goods. Thus one cannot infer a smooth adjustment process even for capacity additions. However, the lumpiness that arises from the non-synchronous exhaustion of capacity need not coincide with lumpiness produced by the process of replacement of old capital goods unless scale economies in capital outlays render it efficient to combine additions and replacement.

When replacement investments for all capital goods are considered, the dynamic programming problem is

$$
V^{R}\left(\mathbf{K}_{\mathbf{t}}\right)=\max _{\left\{X_{j t} y_{j=1}^{m},\left\{K_{h t}\right\}_{h=1}^{n}\right.}\left\{\pi_{t}\left(\mathbf{K}_{\mathbf{t}}, \mathbf{X}_{\mathbf{t}}, T_{t}\right)-\sum_{h=1}^{n} p_{h t} K_{h t}+\beta V\left(\mathbf{K}_{\mathbf{t}+\mathbf{1}}\right)\right\},
$$

subject to $\mathbf{K}_{\mathbf{t}+\mathbf{1}}=\left(q\left(T_{1 t}\right) K_{1 t}, \ldots, q\left(T_{n t}\right) K_{n t}\right)$. The replaced investment of capital good $h$ will be chosen, given all the other capital goods, if $V^{R h}\left(\mathbf{K}_{\mathbf{t}}\right)>V^{A}\left(\mathbf{K}_{\mathbf{t}}\right)$ where the superscript " $R h$ " denotes the choice of replaced investment of capital good $h$. This option is defined as

(6c) $V^{R h}\left(\mathbf{K}_{\mathbf{t}}\right)=\max _{\left\{X_{j t}\right\}_{j=1}^{m},\left\{I_{i t+1}\right\}_{i \neq h}, K_{h t}}\left\{\pi_{t}\left(\mathbf{K}_{\mathbf{t}}, \mathbf{X}_{\mathbf{t}}, T_{t}\right)-\frac{1}{2} \sum_{i \neq h}^{n} b_{i} I_{i t+1}-p_{h} K_{h t}+\beta V\left(\mathbf{K}_{-h \mathbf{t}+\mathbf{1}}, q_{h t} K_{h t}\right)\right\}$ where $\mathbf{K}_{-h \mathbf{t}+\mathbf{1}}$ denotes a vector of capital stocks for all capital goods without replacement except for capital good $h$. The value function given by (6c) yields

$$
\frac{\partial V^{R h}\left(\mathbf{K}_{\mathbf{t}}\right)}{\partial p_{h}}<0, \frac{\partial V^{R h}\left(\mathbf{K}_{\mathbf{t}}\right)}{\partial T_{t}}>0, \frac{\partial V^{R h}\left(\mathbf{K}_{\mathbf{t}}\right)}{\partial T_{h t}}>0, \frac{\partial V^{R h}\left(\mathbf{K}_{\mathbf{t}}\right)}{\partial T_{l t}}<0 \text { for } h \neq l
$$

This shows that the higher the price of the replaced capital good and the higher the rate of technical change of the non-replaced capital goods, the lower is $V^{R h}\left(\mathbf{K}_{\mathbf{t}}\right)$. However, 
$V^{R h}\left(\mathbf{K}_{\mathbf{t}}\right)$ increases with industry rate of technical change and the rate of technical change of the replaced capital good.

Assuming a constant rate of technical change of each capital good over time, the quality of the new relative to the old capital good depends on the number of elapsed periods as well as on its rate of technical change. That is, cumulative technical change increases with plant age and the likelihood that $V^{R h}\left(\mathbf{K}_{\mathbf{t}}\right)>V^{A}\left(\mathbf{K}_{\mathbf{t}}\right)$ increases as a plant ages. Thus, while capacity additions to old plants generally decline over time, replacement capital outlays follow a more complex pattern. As can be seen from equation (8), assuming a constant rate of growth in demand and a constant rate of technical change over time, more expensive capital goods will be replaced later since a larger cumulative change in technology is required to justify replacement. On this point, our analysis follows closely that of Jovanovic and Stolyarov (2000).

The replacement activity yields bursts of investment with bunching of replacement outlays. This, in turn, produces investment cycles with intervals of rising and falling investment. Hence, even if there were no non-convexities in costs for capacity additions, the replacement component of total investment is sufficient to produce cycles in investment activity. Ultimately, however, the increasing non-compatibility between old assets acquired when the plant was born and new assets affect replacement as it does additions to capacity. Thus, as a plant ages, replacement investment will ultimately trend downwards. The higher the rate of technical change, the shorter will be the duration of the cycle since replacement of more expensive capital goods will be justified sooner. And the higher the rate of technical change, the steeper will be the long-term downward trajectory of investment outlays on old plants. 
The model of investment outlays we have presented is derived from a production function that deviates in an important respect from conventional production functions. Specifically, old capital and new capital enter as separate but complementary inputs. Thus in assessing the optimal level of investment, complementarities between old and new capital need to be considered much as complementarities between physical and human capital. While our analysis focuses on the microeconomic pattern of investment at the plant level, it has implications for macroeconomic models and for the analysis of investment across economies - a subject on which we briefly comment later.

\section{Data and Observed Patterns of Investment}

Our data are drawn from the U.S. Census Bureau's Longitudinal Research Database for manufacturing plants. We selected plants that were coded as new in the period 1973-87 subject to two restrictions. First, all so-called new plants were excluded from our sample if the cumulative capital expenditures for the first three years of the plant's life were less than 75 percent of total assets at the end of the third year. This procedure was followed to exclude plants that, in fact, were born prior to the first year of their recorded life or that may have had a prior incarnation and were miscoded as completely new. Moreover, where the 75 percent criterion was not met, we did not have sufficient information for our analysis on investment in the early life of the plant. The second restriction involved inclusion of plants in our sample only if there were continuous data for them. ${ }^{7}$

The resulting sample left us with a non-balanced panel of 5,979 plants with 42,194 observations for these plants in the pooled time series cross-section for the period 
1973-96. Thus, the average interval for which we had continuous data for a plant was roughly 7 years but ranged to a maximum of 24 years for some plants.

Assuming there were no coding errors, the fact that a plant remained in our record for less than 24 years is attributable to one of three factors: (a) it died prior to 1996, (b) it was still alive in 1996 but was born after 1973 (some as late as 1987), (c) the plant was not in the certainty sample. The third reason requires a brief explanation. The certainty of inclusion sample for inter-census years consists of plants with 250 and more employees plus some plants needed for adequate representation for selected product lines. It accounts for roughly two-thirds of the total sample in the Annual Survey of Manufactures. The remainder is sampled subject, however, to the further condition that the composition of this portion of the sample shall change one year following each fiveyear census.

Clearly then, factors (b) and (c) above account for most of the cases of short plant histories in our sample. That is, our data do not encompass for most plants the entire life cycle of the plant.

Table 1 shows the ratios for the sum of the capital outlays in the first three years to total cumulative outlays for plants with recorded histories of varying duration. For plants with a continuous history of just seven years, the above ratio was only .65. By ten years, the ratios were $.58, .51$ and .63 for total capital expenditures, machinery outlays and outlays on buildings, respectively. At twenty years the same ratios were only .31, .28 and .35 .

\footnotetext{
7 . Plants with only one year of missing data were, however, retained in the sample.
} 
Table 1

Capital Expenditures in First Three Years

As a Fraction of Cumulative Outlays*

\begin{tabular}{lrrcc}
\hline & & \multicolumn{3}{c}{ Ratio For } \\
Year & $\mathrm{N}$ & $\mathrm{T}$ & $\mathrm{M}$ & $\mathrm{B}$ \\
\hline 3 & 1640 & 1.00 & 1.00 & 1.00 \\
4 & 1032 & 0.94 & 0.93 & 0.92 \\
5 & 817 & 0.83 & 0.82 & 0.84 \\
6 & 549 & 0.78 & 0.74 & 0.77 \\
7 & 359 & 0.65 & 0.63 & 0.68 \\
8 & 112 & 0.64 & 0.59 & 0.67 \\
9 & 117 & 0.60 & 0.56 & 0.60 \\
10 & 100 & 0.58 & 0.51 & 0.63 \\
11 & 138 & 0.49 & 0.42 & 0.53 \\
12 & 157 & 0.50 & 0.45 & 0.55 \\
13 & 94 & 0.43 & 0.39 & 0.51 \\
14 & 49 & 0.44 & 0.39 & 0.43 \\
15 & 145 & 0.38 & 0.33 & 0.41 \\
16 & 93 & 0.46 & 0.42 & 0.50 \\
17 & 41 & 0.37 & 0.31 & 0.44 \\
18 & 60 & 0.33 & 0.26 & 0.42 \\
19 & 50 & 0.37 & 0.32 & 0.43 \\
20 & 79 & 0.31 & 0.28 & 0.35 \\
21 & 65 & 0.36 & 0.31 & 0.47 \\
22 & 54 & 0.34 & 0.29 & 0.47 \\
23 & 137 & 0.32 & 0.25 & 0.48 \\
24 & 91 & 0.32 & 0.25 & 0.49 \\
\hline
\end{tabular}

Source: Longitudinal Research Data Base.

* The first column designates the number of years for which recorded data exist while $\mathrm{N}$ designates the number of plants in our sample with data limited to the number of years specified in the first column. $\mathrm{T}$ stands for the total capital expenditure ratio, $\mathrm{M}$ for the ratio for machinery expenditures and $\mathrm{B}$ for the expenditures ratio for buildings. 
There are four conclusions to be drawn from Table 1. First, capital expenditures continue at a fairly high rate relative to a plant's initial size for many years. Second, as a plant ages, the magnitude of initial outlays as a fraction of total accumulated outlays continues to diminish but at a diminishing rate. Third, the observed pattern applies to both machinery and structures though subsequent outlays are somewhat larger relative to initial outlays for machinery than for buildings. Indeed, for buildings no further decline in the relative magnitude of initial outlays is observed after the fourteenth year of a plant's life. In contrast, they decline until at least the twenty-third year of a plant's life for machinery. Fourth, for both machinery and for buildings, post-initial capital outlays cannot possibly be explained as replacement of worn-out and physically decaying capital goods. Rather they reflect either capacity expansion or replacement induced by obsolescence since the outlays occur too early in a plant's life to be explained by physical decay.

Some further insight on the latter conclusion may be gained from looking at the spikes in total capital expenditures for individual plants. For this purpose, we define a spike as a peak in total annual capital expenditures for the plant that occurs just prior to a decline in annual outlays. We find that the first spike occurs on the average as early as the sixth year of a plant's life. The second spike occurs on the average in the ninth year and subsequent peaks continue to occur at roughly three-year intervals.

\section{Empirical Model and Estimates.}


We start with the investment outlays of plants as a simple function of their old capital stock and their age as well as the industry technology index. This is based on the empirical implications of equations (7) and (8).

$$
I_{j t}=I\left(K_{j t-1}, a_{j t}, T_{t}\right)
$$

where $I, a, K$ and $T$ denote, respectively, new capital expenditures, the plant's age, stock of old capital goods and the industry technology index. The subscript $j$ identifies the plant and $t$ refers to chronological time in years.

We have shown that investment outlays are a combination of additions of capital goods and of replacement outlays, both of which are complementary to older capital goods. The age variable captures the adaptability of new capital to old capital goods. The cumulative rate of obsolescence specific to the technology index increases with the age of a plant. This is because new capital goods interact with old capital goods less efficiently. As a plant ages, investment outlays should show a long-term downward trajectory with, however, periodic bunching of outlays.

Technological change, however, has a dual effect as explained in Section 1 above. While the adaptability of new capital goods to old capital declines as a plant ages, whether new capital consists of capacity additions or replacement, there is an offsetting effect for replacement outlays. That is, the cumulative change in efficiency of new capital goods rises over time and this effect may dominate outlays on replacement for some interval of time. Even if the path of replacement outlays also ultimately follows a downward trajectory, the rate of decline should be slower than for capacity additions to old plants. Thus as a plant ages, replacement outlays should, at least through a plant's youth and middle age, rise as a fraction of total outlays reducing the rate of decline in 
investment outlays. Ultimately, however, as a plant continues to obsolesce and approaches the end of its economic life, both capacity additions and replacement will approach zero. Thus with a simple specification of the relationship between new and old capital goods as plants age, equation (10) can be written as

$$
I_{j t}=\Phi\left(T_{t}\right) e^{\varphi\left(a_{j t}\right)} K_{j t-1},
$$

where $\varphi\left(a_{j t}\right)=\gamma_{1} a_{j t}+\gamma_{2} a_{j t}{ }^{2}+\gamma_{3} a_{j t}{ }^{3}$. With this specification, for reasons given above, $\gamma_{1}$ and $\gamma_{3}$ are expected to be negative while $\gamma_{2}$ should be positive while replacement outlays are rising as a fraction of total investment.

A key difference between our model and the usual specification that explains bunching of capital outlays in terms of non-convex adjustment costs is that the latter assumes investment is independent of plant age. Our theoretical framework in Section 1 with multiple classes of capital goods offers an alternative explanation to non-convexity in adjustment costs for the bunching of outlays. Equation (11), however, is too simple an application of that framework to capture the recurrent spikes of investment that arise from each plant's specific configuration of capital goods and their associated obsolescence rates. To the extent that our empirical model (specified below) is partly derived from equation (11), and to the extent that a third degree polynomial in age fails to capture the investment spikes unique to each plant, the resulting $R^{2}$ will be reduced accordingly.

To estimate our model in its empirical specification, we introduce a measure of the stock of old capital goods of a plant at time $t$, which consists of the cumulative gross investment streams from the birth of a plant to $t-1$. Our assumptions about complementarity between old and new capital goods imply that both capacity additions 
and replacement outlays in $t$ - not just replacement - will be strongly related to the stock of capital goods in $t-1$. Moreover, this relation will depend on the size of the gross stock rather than on its net value after obsolescence has been subtracted.

For an industry technology index, we use the classification of high and low technology based on Hadlock, Hecker and Gannon (1991). ${ }^{8}$ The technology variable is equal to one if a plant is based in a low technology industry and two if it is based in a high technology industry. It will be recalled that a higher rate of technical change reduces the adaptability of new to old capital goods and in this way has a negative effect on investment both for capacity additions and for replacement. This, however, is at least partially offset by the positive effect of technical change on the relative efficiency of new capital goods and, hence, on the rate at which older capital goods are replaced. The net effect of a higher rate of technical change on the investment outlays of a plant for any given span of time can, therefore, only be ascertained empirically.

A further elaboration of the model takes the form of two additional control variables, one related to plant and another to industry attributes. These consist of (a) the initial labor intensiveness of the plant (that is, shortly after its birth) measured by the ratio of employment to the capital stock of a plant in its third year of life and (b) rate of change in industry demand, measured by shipments at the relevant 4-digit SIC level and lagged one year. That is, $G_{t}=\frac{D_{t}-D_{t-1}}{D_{t-1}}$ where $G$ stands for rate of growth in demand, $D$ for shipments and $t$ for time.

\footnotetext{
${ }^{8}$. Industries were classified as high or low technology on the basis of the proportion of their total employment engaged in R\&D. This was done at the 3-digit SIC level of detail.
} 
The relevance of the initial labor intensiveness of a plant rests on the proposition that technical change tends to be labor saving. Hence, the larger the initial labor input, the greater are the opportunities for replacing old with new capital goods. The relevance of rate of change in industry demand rests on the assumption that when the change is positive and relatively high, individual plants are likely to be producing at their production frontier. Of course growth in the plant's own shipments would be even more directly related to production at the frontier but this variable, in the context of our model, is endogenous and, hence, inappropriate.

We are now ready to test equation (12) below.

$$
\begin{aligned}
\log I_{j t} & =\gamma_{0}+\gamma_{1} a_{j t}+\gamma_{2} a_{j t}{ }^{2}+\gamma_{3} a_{j t}{ }^{3}+\gamma_{4} \log K_{j t-1} \\
& +\gamma_{5} N_{j t}+\gamma_{6} \log T_{t}+\gamma_{7} G_{t}+u_{j t},
\end{aligned}
$$

where $I, a, K, N, T$ and $G$ denote, respectively, capital expenditures, age, old capital stock, labor intensiveness, industry technology index and rate of change in industry demand. The subscript $j$ refers to a plant and $t$ refers to chronological time in years. The measures of all the capital and industry demand variables are in 1987 dollars, deflated with the GDP deflator in the NBER-CES Bartlesman-Becker-Gray database. ${ }^{9}$

We measure capital expenditures by total capital expenditures (TCE), new machinery expenditures (NM) or new building expenditures (NB). As a smoothing device, and also to minimize loss of data that results from the use of a log specification in conjunction with the presence of zero values for some annual plant capital outlays, capital outlays were expressed as three-year moving averages centered on the relevant years. Because the data are predominantly cross-sectional and the panel of plants is highly

\footnotetext{
9 . http://www.nber.org/nberces.
} 
Table 2

Results for Equation (12)*

\begin{tabular}{|c|c|c|c|c|c|c|c|c|c|}
\hline \multirow[b]{2}{*}{ Variables } & \multicolumn{3}{|c|}{$\log (\mathrm{TCE})$} & \multicolumn{3}{|c|}{$\log (\mathrm{NM})$} & \multicolumn{3}{|c|}{$\log (\mathrm{NB})$} \\
\hline & $\begin{array}{c}\text { All } \\
\text { plants }\end{array}$ & $S \geq 10$ & $S \geq 20$ & $\begin{array}{c}\text { All } \\
\text { plants }\end{array}$ & $S \geq 10$ & $S \geq 20$ & $\begin{array}{c}\text { All } \\
\text { plants }\end{array}$ & $\begin{array}{c}S \geq \\
10\end{array}$ & $\begin{array}{l}S \geq \\
20\end{array}$ \\
\hline Constant & $\begin{array}{r}-0.1390 \\
(-3.38)\end{array}$ & $\begin{array}{r}0.0733 \\
(1.39)\end{array}$ & $\begin{array}{r}-0.1172 \\
(-1.72)\end{array}$ & $\begin{array}{l}-0.6620 \\
(-19.53)\end{array}$ & $\begin{array}{l}-0.7807 \\
(-16.58)\end{array}$ & $\begin{array}{l}-1.1046 \\
(-17.23)\end{array}$ & $\begin{array}{l}-2.1330 \\
(-42.34)\end{array}$ & $\begin{array}{l}-1.9988 \\
(-21.91)\end{array}$ & $\begin{array}{l}-1.8257 \\
(-12.17)\end{array}$ \\
\hline Age & $\begin{array}{l}-1.1096 \\
(-65.04)\end{array}$ & $\begin{array}{l}-0.7877 \\
(-44.89)\end{array}$ & $\begin{array}{l}-0.6887 \\
(-31.45)\end{array}$ & $\begin{array}{c}-0.6990 \\
(-54.44)\end{array}$ & $\begin{array}{l}-0.6711 \\
(-43.12)\end{array}$ & $\begin{array}{l}-0.5491 \\
(-27.04)\end{array}$ & $\begin{array}{l}-0.6222 \\
(-33.04)\end{array}$ & $\begin{array}{r}-0.8886 \\
(-29.68)\end{array}$ & $\begin{array}{c}-0.8317 \\
(-18.89)\end{array}$ \\
\hline $\mathrm{Age}^{2}$ & $\begin{array}{c}0.0996 \\
(54.31)\end{array}$ & $\begin{array}{l}0.0576 \\
(32.80)\end{array}$ & $\begin{array}{l}0.0512 \\
(24.37)\end{array}$ & $\begin{array}{l}0.0577 \\
(39.74)\end{array}$ & $\begin{array}{l}0.0507 \\
(30.42)\end{array}$ & $\begin{array}{l}0.0371 \\
(17.84)\end{array}$ & $\begin{array}{l}0.0437 \\
(20.24)\end{array}$ & $\begin{array}{l}0.0642 \\
(20.68)\end{array}$ & $\begin{array}{c}0.0498 \\
(11.47)\end{array}$ \\
\hline $\mathrm{Age}^{3}$ & $\begin{array}{l}-0.0027 \\
(-47.43)\end{array}$ & $\begin{array}{l}-0.0014 \\
(-26.66)\end{array}$ & $\begin{array}{l}-0.0013 \\
(-21.65)\end{array}$ & $\begin{array}{c}-0.0014 \\
(-31.28)\end{array}$ & $\begin{array}{c}-0.0012 \\
(-23.43)\end{array}$ & $\begin{array}{l}-0.0008 \\
(-13.35)\end{array}$ & $\begin{array}{r}-0.0010 \\
(-13.70)\end{array}$ & $\begin{array}{r}-0.0015 \\
(-15.66)\end{array}$ & $\begin{array}{r}-0.0009 \\
(-7.49)\end{array}$ \\
\hline $\log (\mathrm{K})$ & $\begin{array}{r}0.9825 \\
(168.47)\end{array}$ & $\begin{array}{r}0.9280 \\
(141.09)\end{array}$ & $\begin{array}{r}0.9479 \\
(113.46)\end{array}$ & $\begin{array}{r}0.8603 \\
(220.57)\end{array}$ & $\begin{array}{r}0.9224 \\
(160.14)\end{array}$ & $\begin{array}{r}0.9754 \\
(122.49)\end{array}$ & $\begin{array}{c}0.6518 \\
(97.35)\end{array}$ & $\begin{array}{r}0.8319 \\
(69.22)\end{array}$ & $\begin{array}{c}0.9045 \\
(49.02)\end{array}$ \\
\hline $\mathrm{N}$ & $\begin{array}{c}0.0004 \\
(11.59)\end{array}$ & $\begin{array}{c}0.0049 \\
(18.81)\end{array}$ & $\begin{array}{l}0.0067 \\
(12.06)\end{array}$ & $\begin{array}{r}0.0002 \\
(6.36)\end{array}$ & $\begin{array}{l}0.0051 \\
(20.65)\end{array}$ & $\begin{array}{c}0.0071 \\
(13.55)\end{array}$ & $\begin{array}{r}0.0001 \\
(0.43)\end{array}$ & $\begin{array}{r}0.0059 \\
(8.92)\end{array}$ & $\begin{array}{r}0.0079 \\
(5.57)\end{array}$ \\
\hline $\mathrm{T}$ & $\begin{array}{c}0.1959 \\
(11.13)\end{array}$ & $\begin{array}{r}0.1567 \\
(8.60)\end{array}$ & $\begin{array}{r}0.0580 \\
(2.53)\end{array}$ & $\begin{array}{c}0.2718 \\
(18.03)\end{array}$ & $\begin{array}{c}0.2494 \\
(13.78)\end{array}$ & $\begin{array}{r}0.1447 \\
(6.03)\end{array}$ & $\begin{array}{r}0.2457 \\
(9.73)\end{array}$ & $\begin{array}{r}0.2231 \\
(6.19)\end{array}$ & $\begin{array}{r}0.0484 \\
(0.88)\end{array}$ \\
\hline G & $\begin{array}{r}0.7282 \\
(9.33)\end{array}$ & $\begin{array}{r}0.6884 \\
(7.70)\end{array}$ & $\begin{array}{r}0.3465 \\
(3.14)\end{array}$ & $\begin{array}{r}0.6016 \\
(9.28)\end{array}$ & $\begin{array}{r}0.6809 \\
(7.97)\end{array}$ & $\begin{array}{r}0.5104 \\
(4.83)\end{array}$ & $\begin{array}{r}0.1465 \\
(1.40)\end{array}$ & $\begin{array}{r}0.6115 \\
(3.51)\end{array}$ & $\begin{array}{r}0.4537 \\
(1.75)\end{array}$ \\
\hline $\mathrm{R}^{2}$ & 0.57 & 0.50 & 0.52 & 0.58 & 0.52 & 0.53 & 0.31 & 0.26 & 0.26 \\
\hline
\end{tabular}

* Estimates are based on data from the LRD at the U.S. Bureau of the Census. Heteroskedasticity-corrected $\mathrm{t}$-values are in parentheses. The dependent variable is $\log$ of three-year centered moving average of total capital expenditures (TCE), new machinery expenditures (NM) or new building expenditures (NB). S refers to the number of years of continuous data for the plant. The explanatory variables $\mathrm{K}, \mathrm{N}, \mathrm{T}$ and $\mathrm{G}$ denote old capital, initial labor intensiveness, industry technology index and rate of growth in industry demand, respectively. The industry technology index variable is categorical with a value of 2 for high technology industries and of 1 for low technology industries. The total sample consists of 5,979 plants, 1,353 plants for $S \geq 10,426$ plants for $S \geq 20$. 
unbalanced, serial correlation is most unlikely to be important and a Durbin-Watson statistic is not shown.

The results for equation (12) are shown in Table 2 and indicate that all the coefficients of the explanatory variables are associated with high t-values and significant at the $1 \%$ level. In general, they strongly support the predicted relations. Notwithstanding the fact that our empirical model is too simple to explain recurrent spikes in investment, the correlations were all quite high for cross-section data.

The results may be summarized as follows:

(a) The coefficient of old capital goods is positive, highly significant and close to unity in $\log$ specification at least for total capital expenditures and for machinery. This reflects strong complementarity between old and new capital expenditures and supports the specification of equation (11).

(b) The capital expenditure of plants decline with the age of plants, but not monotonically. The age variable has a negative impact on the capital expenditures of plants. This implies that complementarity between old and new capital goods declines with the age of plants. The positive coefficient of age ${ }^{2}$ is consistent with predictions for the interval that replacement rises as a fraction of total investment. The coefficient of age $^{3}$ is significant and also has the predicted sign but the coefficient is quite low. This is probably because few plants in our sample were approaching the end of their economic lives.

(c) The industry technology index shows that plants in high technology industries were associated with more capital expenditures than those in the low technology industries. The index was hypothesized to have a negative impact on additions of new to old capital 
Table 3

Alternative Specifications of the empirical Model*

\begin{tabular}{|c|c|c|c|}
\hline \multirow{2}{*}{$\begin{array}{c}\text { Variables } \\
\text { Constant }\end{array}$} & \multicolumn{3}{|c|}{$\log (\mathrm{TCE})$} \\
\hline & $\begin{array}{l}-0.6634 \\
(-21.42)\end{array}$ & $\begin{array}{r}0.0755 \\
(2.11)\end{array}$ & $\begin{array}{r}-0.2739 \\
(-7.06)\end{array}$ \\
\hline Age & $\begin{array}{l}-0.7282 \\
(-70.46)\end{array}$ & $\begin{array}{l}-1.1078 \\
(-64.94)\end{array}$ & $\begin{array}{l}-1.2493 \\
(-76.05)\end{array}$ \\
\hline $\mathrm{Age}^{2}$ & $\begin{array}{r}0.0735 \\
(59.42)\end{array}$ & $\begin{array}{r}0.0996 \\
(54.27)\end{array}$ & $\begin{array}{l}0.1101 \\
(64.80)\end{array}$ \\
\hline $\mathrm{Age}^{3}$ & $\begin{array}{l}-0.0020 \\
(-50.14)\end{array}$ & $\begin{array}{l}-0.0027 \\
(-47.43)\end{array}$ & $\begin{array}{l}-0.0029 \\
(-56.93)\end{array}$ \\
\hline $\log (K)$ & & $\begin{array}{r}0.9815 \\
(168.96)\end{array}$ & $\begin{array}{r}1.0875 \\
(182.05)\end{array}$ \\
\hline $\log (\mathrm{IK})$ & $\begin{array}{r}0.8966 \\
(192.26)\end{array}$ & & \\
\hline $\mathrm{N}$ & $\begin{array}{r}0.0003 \\
(9.91)\end{array}$ & $\begin{array}{r}0.0004 \\
(11.63)\end{array}$ & \\
\hline $\log (\mathrm{N})$ & & & $\begin{array}{r}0.2724 \\
(65.34)\end{array}$ \\
\hline $\mathrm{T}$ & $\begin{array}{c}0.1704 \\
(10.30)\end{array}$ & & $\begin{array}{l}0.1932 \\
(11.46)\end{array}$ \\
\hline $\mathrm{T}_{1}$ & & $\begin{array}{l}0.0371 \\
(13.58)\end{array}$ & \\
\hline G & $\begin{array}{r}0.5170 \\
(7.18)\end{array}$ & $\begin{array}{r}0.7207 \\
(9.17)\end{array}$ & $\begin{array}{r}0.7604 \\
(10.48)\end{array}$ \\
\hline $\mathrm{R}^{2}$ & 0.57 & 0.57 & 0.59 \\
\hline
\end{tabular}

* Estimates are based on data from the LRD at the U.S. Bureau of the Census. Heteroskedasticity-corrected $\mathrm{t}$-values are in parentheses. The Dependent variable is $\log$ of three-year centered moving average of total capital expenditures (TCE). The explanatory variable IK denotes initial capital. $\mathrm{T}_{1}$ is the measured coefficient of the time variable for the equation (13). All the other variables are defined in table 2 . The sample consists of 5,979 plants. 
goods for capacity expansions and, on balance, probably a positive impact on replacement outlays. The positive relationship between capital expenditures and the index suggests that the effect on replacement outlays dominates.

(d) As predicted, high labor intensiveness raised opportunities for replacement and, thereby total capital expenditures. The effect, as might be expected, was stronger for machinery than for buildings. For the latter it was ambiguous.

(e) Rate of growth in industry demand had a clear impact on capital outlays for machinery but not for buildings. The effect of inclusion of the variable on $\mathrm{R}^{2}$ was, however, negligible.

\section{$\underline{\text { Robustness }}$}

Equation (12), as Table 2 indicates, was estimated for various samples of plants, i.e., all new plants, those with continuous data for 10 years or more, and those with continuous data for 20 years or more. While the samples differed greatly in size, the results for all samples were very similar.

As a further test of robustness, the specification of two other variables was changed. In estimating equation (12), we measured the stock of old capital goods of a plant at time $t$ by the cumulative gross investment stream from the birth to $t-1$. An alternative hypothesis is that what is decisive is the initial stock of capital measured by cumulative capital expenditures in the first three years of the plant's life. Moreover, an alternative measure was used to assess the rate of technical change for the industry. Specifically, the following specification for the industry technology index was introduced: 
(13) Total value added $=\Psi$ (Production worker hours, chronological time in years).

The information is derived from the NBER-CES Bartlesman-Becker-Gray database. The regression is carried out with time-series data for each U.S. manufacturing industry at the 4-digit SIC level for the periods 1965-1980 and for 1981-1996. The coefficients of the time variable were then alternative proxies (each for its time interval) for the industry technology index.

The results with these alternative specifications are shown in Table 3. Once again, the results appear to be quite stable and support the previously reported conclusions. Similarly, expressing the labor intensiveness measure in a log specification changes the results very little.

\section{Conclusions}

We have specified a dynamic programming model with multiple categories of capital goods which purports to explain capital expenditures on existing plants over their lives. The central element of our model is the complementarity between old and new capital goods.

The empirical specification of our model, while too simple to explain recurrent spikes in investment activity, nevertheless offers a reasonably good explanation of the observed phenomena. Specifically, the estimates point to (a) complementarities between old and new capital goods as an explanation of investment on existing plants, (b) a negative slope to investment over time as plants age but with a diminishing rate of decline as the fraction of total investment attributed to replacement rises, (c) a complex relation between the rate of technical change for an industry and plant investment activity 
with, on balance, a positive net effect of higher rates of technical change (at least through the mid-life of a plant) and (d) a positive effect on future plant investment of a high initial level of labor intensiveness of production.

Complementarity, which effectively raises the productivity of capital outlays on existing as compared with on new plants, helps explain a puzzling phenomenon. Specifically, why is investment in capital goods much larger in developed economies notwithstanding the much lower price of the complementary labor input in the less developed economies? The usual explanation focuses on the greater availability of human capital and on the physical infrastructure in developed economies. We now offer a supplementary explanation. Old capital goods are complementary to new capital goods much as human capital complements physical capital. This raises the productivity of new investment where it can interact with existing capital.

In much the same way, it explains an entry barrier to new firms in mature industries. The usual explanations of market entrenchment and learning by doing which are used to show why leading firms often retain their position for long spans of time now can be supplemented. Firms with existing capital have an advantage over new entrants in the form of complementarity between old and new capital. 


\section{References}

Bertola, Ginseppe, and Caballero, Ricardo, "Kinked Adjustment Costs and Aggregate Dynamics," NBER Macroeconomics Annual 1990, O.J. Blanchard and S. Fischer Eds.

Boddy, Raford and Gort, Michael, "The Substitution of Capital for Capital," Review of Economics and Statistics, May 1971, 53(2), pp. 179-188.

Cooper, Russel; Haltiwanger, John and Power, Laura, "Machine Replacement and the Business Cycle: Lumps and Bumps," American Economic Review, September 1999, 89(4), pp. 921-946.

Doms, Mark and Dunne, Timothy "Capital Adjustment Patterns in Manufacturing Plants," Center for Economic Studies. U.S. Bureau of the Census, Working Paper,1994.

Feldstein, Martin and Rothschild, Michael, "Towards an Economic Theory of Replacement Investment," Econometrica, May 1974, 42(3), pp. 393-423.

Gould, John, "Adjustment Costs in the Theory of Investment of the Firm," Review of Economic Studies, January 1968, 35(1), pp. 47-55.

Hadlock, Paul; Hecker, Daniel and Gannon, Joseph, "High Technology Employment: Another View," Monthly Labor Review, July 1991, 114 (7), pp. 26-30.

Hayashi, Fumio, "Tobin's Marginal and Average q: A Neoclassical Interpretation," Econometrica, January 1982, 50(1), pp. 213-224.

Jovanovic, Boyan and Stolyarov, Dmitriy, "Optional Adoption of Complementary Technologies,” American Economic Review, March 2000, 90(1), pp. 15-29.

Lucas, Robert, "Adjustment Costs and the Theory of Supply," Journal of Political Economy, 1967, 75(4), pp. 321-334.

Pindyck, Robert, "Irreversibility, Uncertainty and Investment," Journal of Economic Literature, September 1991, 29(3), pp. 1110-1148.

Rothschild, Michael, "On the Cost of Adjustment," Quarterly Journal of Economics, November 1971, 85(4), pp. 605-622. 